\title{
Compact and Broadband Microstrip Antennas for Next Generation High-Speed Wireless Communication Using HIPERLAN/2
}

\author{
Jibendu Sekhar Roy and Milind Thomas \\ Received 23 April 2007; Revised 30 July 2007; Accepted 1 October 2007 \\ Recommended by K. Yazdandoost
}

The investigations on rectangular-slot-loaded and V-slot-loaded proximity-coupled microstrip antennas are reported. The performances of two antennas are investigated for the application in wireless local area network 2 (HIPERLAN/2) using IE3D software and the computed results are verified by measurement. Results show that the antennas have wide bandwidth and moderate gain and may be used as small, compact antennas for HIPERLAN/2 communication.

Copyright ( $) 2007$ J. S. Roy and M. Thomas. This is an open access article distributed under the Creative Commons Attribution License, which permits unrestricted use, distribution, and reproduction in any medium, provided the original work is properly cited.

\section{INTRODUCTION}

The need for wireless broadband communications has increased rapidly in recent years demanding quality of service, security, handover, and increased throughput for the wireless local area networks (WLANs). The mainaimof nextgeneration wireless communication is high-speed networking service for multimedia communication. The most important high-data-rate wireless broadband networking systems for next generation wireless communications areEuropean Telecommunications Standards Institutes (ETSI) High Performance Local Area Network type 1 (HIPERLAN/1), and High Performance Local Area Network type 2 (HIPERLAN/2) which uses the frequency bands $5.150 \mathrm{GHz}-$ $5.350 \mathrm{GHz}$ and $5.470 \mathrm{GHz}-5.725 \mathrm{GHz}$, respectively, with omnidirectional antennas [1]. The modern wireless communication systems requirethe antennas for different systems and standards with characteristicslike compact, broadband, multiple resonant frequencies and moderate gain.Because of many attractive features, microstrip patch antennas have received considerable attention for wireless communication applications [2-8].Single-layer microstrip antennas have very narrow bandwidth, but using two-layer proximitycoupled microstrip antennas higher bandwidth can be achieved [9-13]. The input impedance of a proximitycoupled microstrip antenna is a sensitive function of length and width of the microstrip feed line. Since radiation pattern of a microstrip antenna has wide beamwidth in one hemisphere, two back-to-back microstrip antennas in the same module can be used to produce nearly omnidirectional radiation pattern required for LAN applications. In proximitycoupled microstrip antenna, the radiating patch, fabricated on a dielectric substrate, is excited by a microstrip line on another substrate as shown in Figure 1.The dielectric constant and height of the substrates, used for microstrip patch and microstrip line, may be different.Investigations on slot loaded single-layer microstrip antennas are reported, but research work on slot-loaded proximity-coupled microstrip antennas are insufficient $[4,12,13]$. Compact microstripcan be designed by embedding suitable slots on the radiating patch.The loading can be varied by varying the length and width of the slot.Slots can be of different shapesand some slots or combination of two slotson the patch can produce dual frequencies.

In this paper, the theoretical and experimental studies ontwo new types of proximity-coupled microstrip antennas are reported. Both proximity-coupled microstrip antennas were rectangular type, but one antenna was loaded by cutting rectangular-shapedslot on the patch and other was loaded by V-shaped slot on the patch. Cutting slot on themicrostrip patch, reduced size, compact antenna can be designed $[12,13]$. The geometry of rectangular-slotloaded and V-slot-loaded microstrip radiating patches are shown in Figures 2 and 3, respectively. Results show that the proposed microstrip patch antennas have very small size, wide bandwidth, and moderate gain for the application in HIPERLAN/2. 




FIgURE 1: Proximity-coupled microstrip patch antenna.

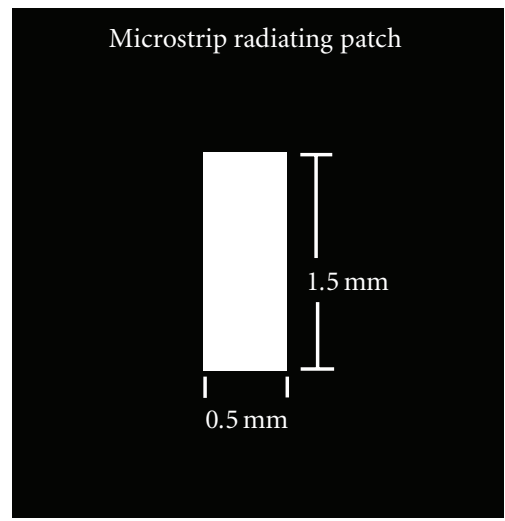

FIgURE 2: Rectangular-slot-loaded microstrip patch.

\section{COMPUTED AND MEASURED RESULTS}

The method of moment using IE3D software is used for the design of the proximity-coupled microstrip antennas. The antennas were fabricated on glass epoxy substrate with dielectric constant 4.36, substrate thickness $1.57 \mathrm{~mm}$, and measurements were done using vector network analyzer (N5230A, Agilent Technologies, USA). The radiation patterns of the antennas were measured using C-band microwave test bench (consisting of Gunn oscillator, PIN modulator, isolator, variable attenuator, and direct-readingabsorption-type frequency meter), Gunn power supply, standard pyramidal Horn antenna (of gain $17 \mathrm{~dB}$ ), and $\mathrm{HP}$ power meter.

Two microstrip antennas, with V-slot and rectangularslot on the center of the rectangular patches, were fed by SMA connectors via very small microstrip lines. The microstrip feed lines were placed below the centers of the V-slot and rectangular-slot. The dimension of the $\mathrm{V}$-slot-loaded microstrip antenna was $12 \mathrm{~mm} \times 4 \mathrm{~mm}$ and the dimension of the rectangular-slot-loaded microstrip antenna was $12 \mathrm{~mm}$ $\times 4.4 \mathrm{~mm}$. The dimensions of the rectangular-slot and Vslot are shown in Figures 2 and 3. The dimension of the feed line was $5 \mathrm{~mm} \times 1 \mathrm{~mm}$. These optimum dimensions of the patches, slots, and feed line were determined using IE3D computation to obtain required frequency for HIPERLAN/2 and to achieve best impedance matching.

The computed return loss of the rectangular-slot-loaded proximity-coupled microstrip patch antenna shows that it

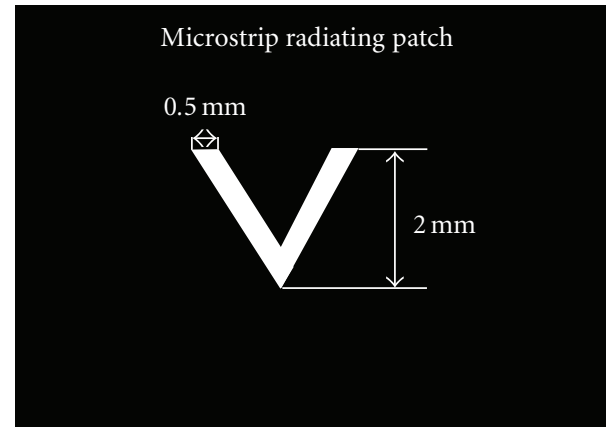

FIGURE 3: V-slot-loaded microstrip patch.

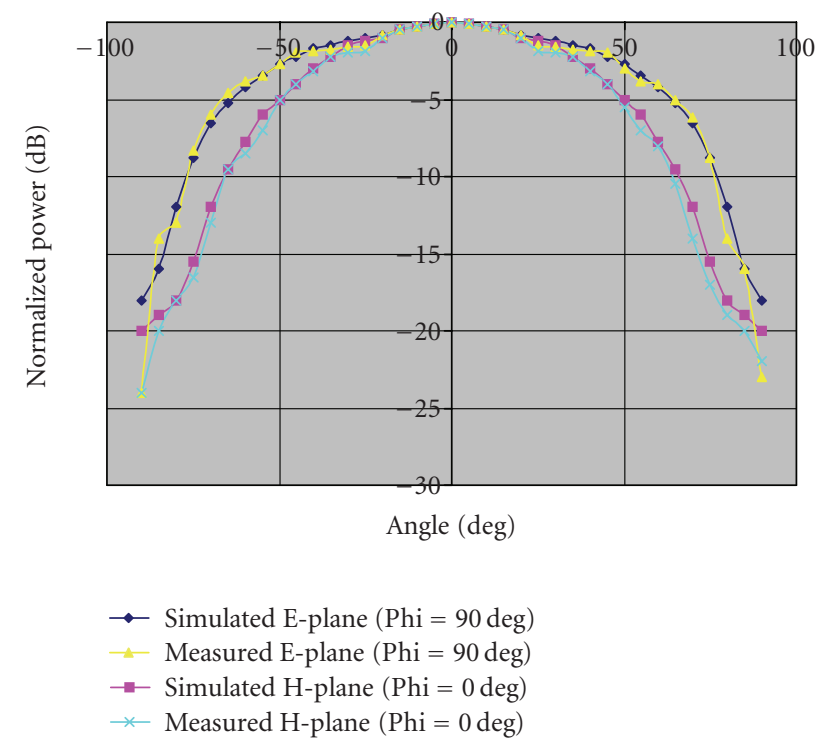

FIGURE 4: Computed and measured radiation patterns of rectangular-slot-loaded proximity-coupled microstripantenna at $5.56 \mathrm{GHz}$.

resonates at $5.56 \mathrm{GHz}$. The antenna shows broadside radiation pattern as shown in Figure 4, where computed and measured results are plotted. The computed gain at $5.56 \mathrm{GHz}$ is $5.3 \mathrm{dBi}$ and minimum gain at the frequency band of $5.470 \mathrm{GHz}-5.725 \mathrm{GHz}$ is $4.5 \mathrm{dBi}$. The computed $10 \mathrm{~dB}$ return loss bandwidth of the antenna is $190 \mathrm{MHz}$. The simulated and measured return losses of the rectangular-slot-loaded proximity-coupled microstrip patch antenna are compared in Figure 5. The computed return loss of the V-slot-loaded proximity-coupled microstrip patch antenna shows that it resonates at $5.565 \mathrm{GHz}$. The antenna shows broadside radiation pattern and shown in Figure 6, where computed and measured results are plotted. The computed gain at $5.565 \mathrm{GHz}$ is $5.3 \mathrm{dBi}$ and minimum gain at the frequency band of $5.470 \mathrm{GHz}-5.725 \mathrm{GHz}$ is $4.7 \mathrm{dBi}$. The computed $10 \mathrm{~dB}$ return loss bandwidth of the antenna is $210 \mathrm{MHz}$. The simulated and measured return losses of the V-slot-loaded proximity-coupled microstrip patch antenna are compared in Figure 7. Microstrip antenna simulation using IE3D software assumes infinite ground plane, whereas in practice, the ground plane is finite. For fabricated rectangular-slot-loaded 




$\longrightarrow$ IE3D result

$\rightarrow$ - Measured result

FIgURE 5: Comparison between simulated and measured return losses for rectangular-slot-loaded proximity-coupled microstrip antenna.

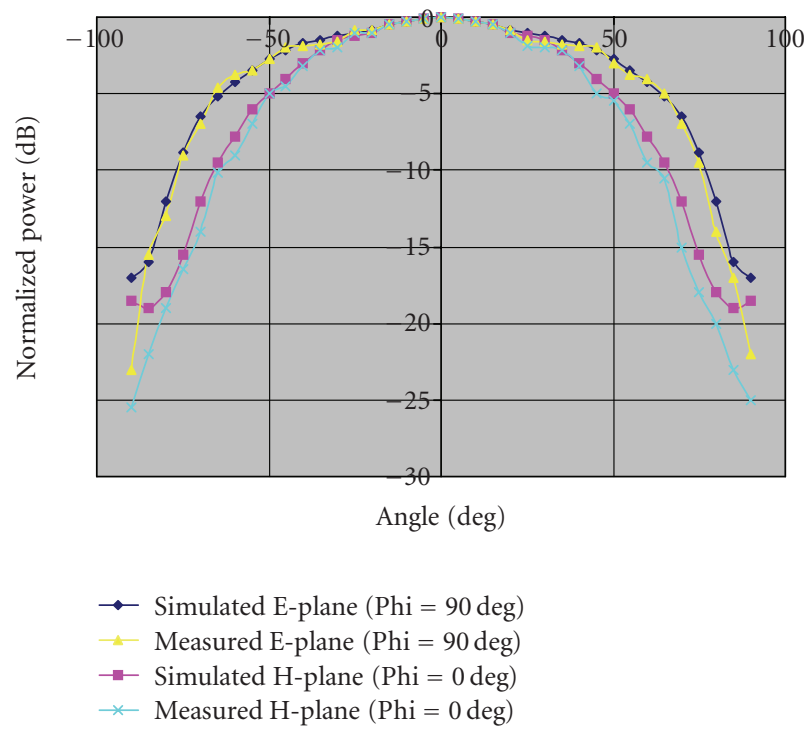

FIgURE 6: Computed and measured radiation patterns of V-slotloaded proximity-coupled microstrip antenna at $5.56 \mathrm{GHz}$.

and V-slot-loaded proximity-coupled microstrip patch antennas, measured here, the dimensions of the ground plane were $25 \mathrm{~mm} \times 25 \mathrm{~mm}$. The small differences between computed and measured radiation patterns, as shown in Figures 4 and 6, are due to the fact that measurements were not performed in anechoic chamber and also simulation using IE3D software considers infinite ground plane, whereas in measurement the ground plane is finite. Due to small ground plane, the diffracted field from the edge, modified the radiation patterns resulting in some ripples. Polarization has not

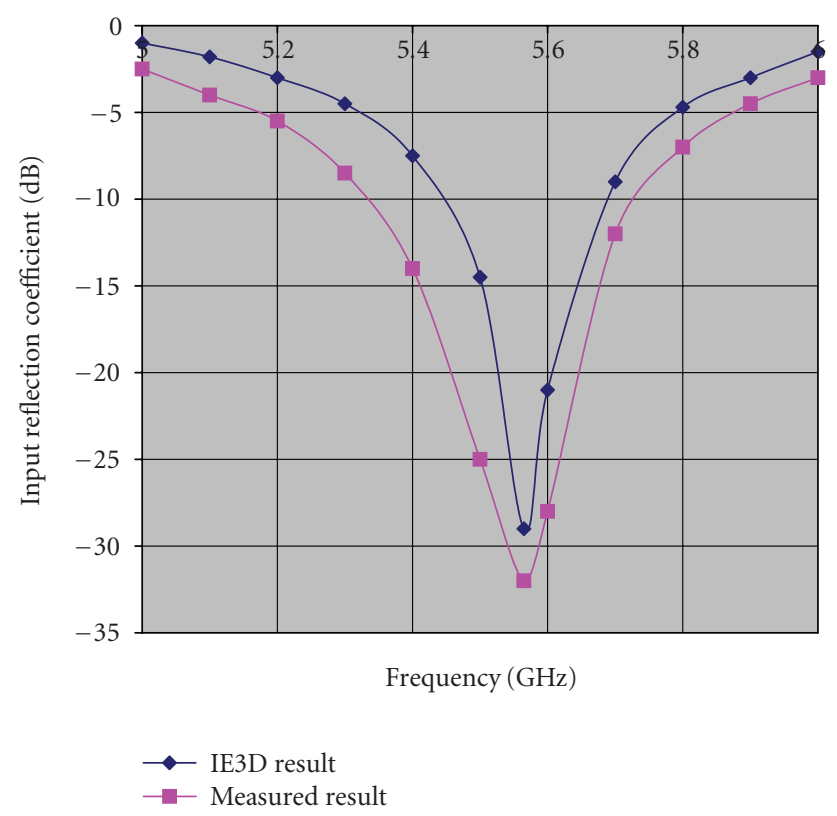

FIgURE 7: Comparison between simulated and measured return losses for V-slot-loaded proximity-coupled microstrip antenna.

been studied in this paper. In mobile communications and in WLAN applications, polarization is not critical. Especially, in urban scenarios, intense reflections and scattering change the polarization of the incoming electromagnetic waves. It is evident from Figures 5 and 7 that there are small differences between simulated and measured results. This is because of the fact that the antennas were not fabricated using multilayered etching technique. The slot-loadedmicrostrip patch was fabricated on one substrate and microstripline was fabricated on other substrateand these two were joined together by thin gumbefore measurement. The difference between simulated and measured return loss bandwidths, shown in Figures 5 and 7 may be due to the effect of thin layer of gum. Another reason of this difference is that perhaps the feed line was not exactly belowthe centres of the V-slot and rectangular-slotloaded patches at the time of measurements, because duringmeasurements it was found that if the feed line is shifted very little, laterally from the centre, bandwidth changes.

\section{CONCLUSION}

The performances of very reduced size broadband microstrip antennas for the application in HIPERLAN/2 communication are reported here. The computation using IE3D shows that in order to achieve same characteristics, in the frequency range of HIPERLAN/2, using proximity-coupled rectangular microstrip antenna without loading by any slot, the required dimension ofpatch should be $12 \mathrm{~mm} \times 10 \mathrm{~mm}$ and for proper impedance matching the dimension of the feed line should be $15 \mathrm{~mm} \times 4 \mathrm{~mm}$. Therefore, using the proposed rectangular-slot-loaded proximity-coupled microstrip antenna the peripheral area of the patch is reduced by $65 \%$ and using V-slot-loaded proximity-coupled microstrip antenna the peripheral area of the patch is reduced by $60 \%$. The feed 
line dimension is reduced by about $90 \%$. The V-slot-loaded proximity-coupled microstrip antenna has more impedance bandwidth than rectangular-slot-loaded proximity-coupled microstrip antenna.Thus, these proposed antennas are truly compact and broadband antennas.

\section{ACKNOWLEDGMENT}

The authors like to acknowledge University Grants Commission (UGC), New Delhi, India, for providing financial assistance during this research work.

\section{REFERENCES}

[1] R. Van Nee and R. Prasad, OFDM for Wireless Multimedia Communications, Universal Personal Communications, Artech House, Boston, Mass, USA, 2000.

[2] J. Ollikainen, M. Fischer, and P. Vainikainen, "Thin dualresonant stacked shorted patch antenna for mobile communications," Electronics Letters, vol. 35, no. 6, pp. 437-438, 1999.

[3] F. Yang, X.-X. Zhang, X. Ye, and Y. Rahmat-Samii, "Wide-band E-shaped patch antennas for wireless communications," IEEE Transactions on Antennas and Propagation, vol. 49, no. 7, pp. 1094-1100, 2001.

[4] R. Garg, P. Bhartia, I. J. Bahl, and A. Ittipiboon, Microstrip Antenna Design Handbook, Artech House, Boston, Mass, USA, 2001.

[5] J. S. Roy, N. Chattoraj, and N. Swain, "Short-circuited microstrip antennas for multiband wireless communications," Microwave and Optical Technology Letters, vol. 48, no. 12, pp. 2372-2375, 2006.

[6] H.-D. Chen, J.-N. Li, and Y.-F. Huang, "Band-notched ultrawideband square slot antenna," Microwave and Optical Technology Letters, vol. 48, no. 12, pp. 2427-2429, 2006.

[7] J. S. Roy and N. Swain, "A new dual-frequency microstrip patch antenna for GPS and bluetooth systems," in Proceedings of the 3rd International Conference on Microwaves, Antenna, Propagation and Remote Sensing (ICMARS '06), Jodhpur, India, December 2006.

[8] J. S. Roy, N. Chattoraj, and N. Swain, "New dual-frequency microstrip antennas for wireless communication," Romanian Journal of Information Science and Technology, vol. 10, no. 1, pp. 113-119, 2007.

[9] D. M. Pozar and S. M. Voda, "A rigorous analysis of a microstripline fed patch antenna," IEEE Transactions on Antennas and Propagation, vol. 35, no. 12, pp. 1343-1350, 1987.

[10] J. S. Roy, S. K. Shaw, P. Paul, D. R. Poddar, and S. K. Chowdhury, "Some experimental investigations on electromagnetically coupled microstrip antennas on two-layer substrates," Microwave and Optical Technology Letters, vol. 4, no. 6, pp. 236-238, 1991

[11] S. M. Duffy, "An enhanced bandwidth design technique for electromagnetically coupled microstrip antennas," IEEE Transactions on Antennas and Propagation, vol. 48, no. 2, pp. 161-164, 2000.

[12] K.-L. Wong, Compact and Broadband Microstrip Antennas, John Wiley \& Sons, New York, NY, USA, 2002.

[13] G. Kumar and K. P. Ray, Broadband Microstrip Antennas, Artech House, Boston, Mass, USA, 2003.

\section{AUTHOR CONTACT INFORMATION}

Jibendu Sekhar Roy: International Centre for Wireless and Mobile Communication, Electronics and Communication Engineering Department, Birla Institute of Technology (Deemed University), Mesra 835215, Ranchi, India; drjsroy@rediffmail.com

Milind Thomas: International Centre for Wireless and Mobile Communication, Electronics and Communication Engineering Department, Birla Institute of Technology (Deemed University), Mesra 835215, Ranchi, India; milind_thomas@hotmail.com 

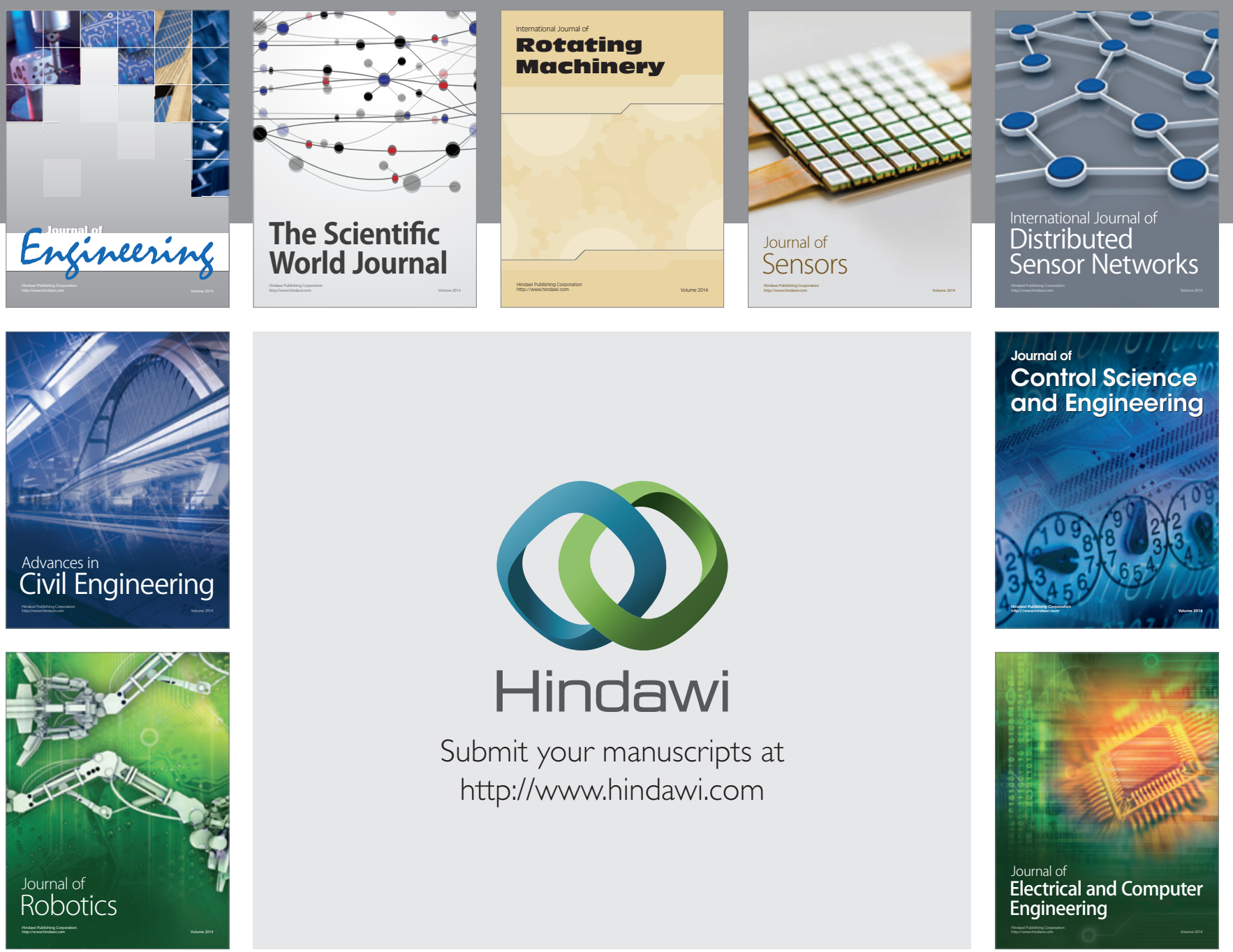

Submit your manuscripts at

http://www.hindawi.com
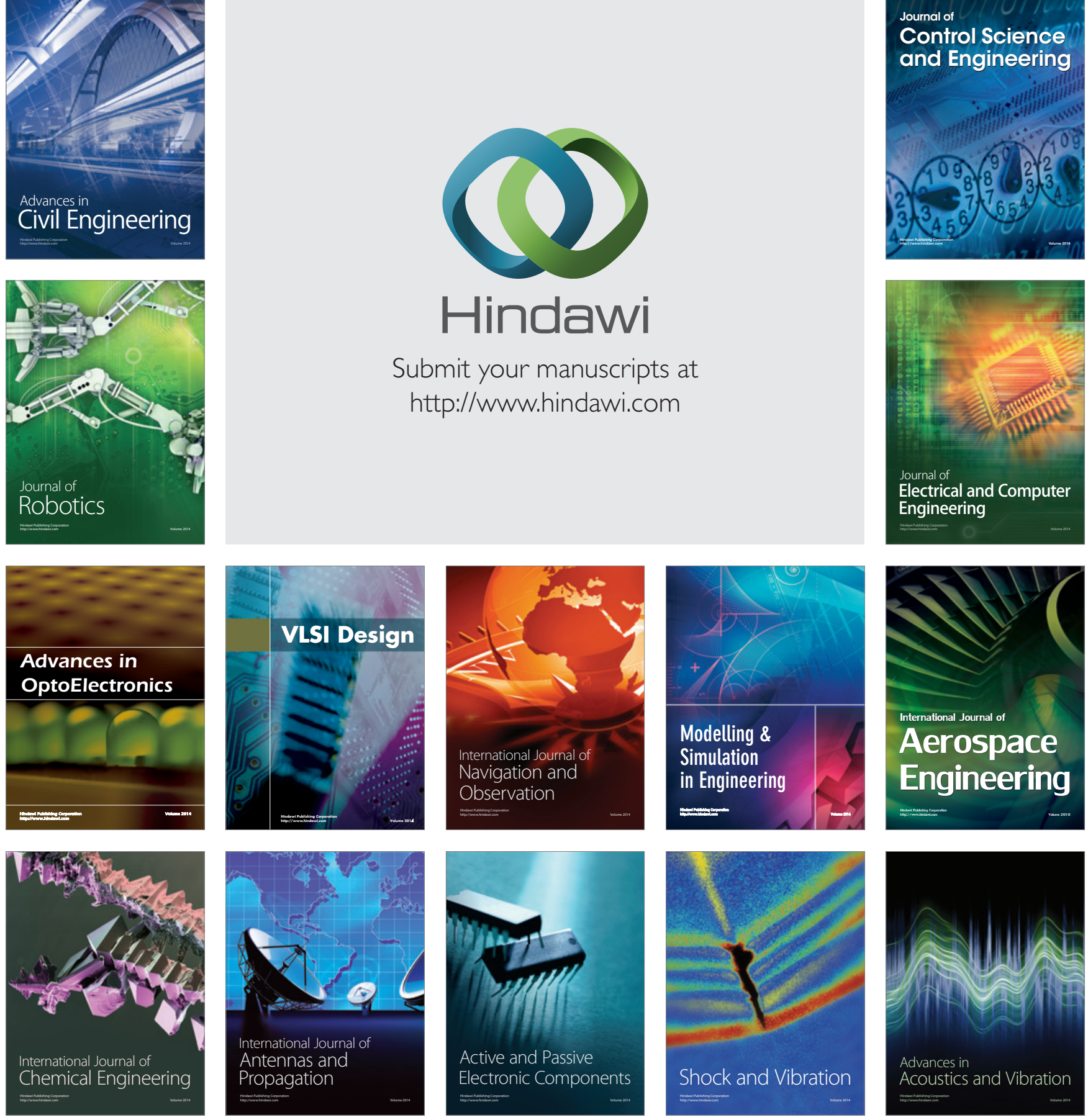